City University of New York (CUNY)

CUNY Academic Works

\title{
Multi-Scale Predictors of Parasite Risk in Wild Male Savanna Baboons (Papio Cynocephalus)
}

\author{
Bobby Habig \\ CUNY Queens College \\ David A.W.A.M. Jansen \\ University of Notre Dame \\ Mercy Y. Akinyi \\ Duke University \\ Laurence R. Gesquiere \\ Duke University
}

Susan C. Alberts

Duke University

See next page for additional authors

\section{How does access to this work benefit you? Let us know!}

More information about this work at: https://academicworks.cuny.edu/qc_pubs/343

Discover additional works at: https://academicworks.cuny.edu

This work is made publicly available by the City University of New York (CUNY).

Contact: AcademicWorks@cuny.edu 


\section{Authors}

Bobby Habig, David A.W.A.M. Jansen, Mercy Y. Akinyi, Laurence R. Gesquiere, Susan C. Alberts, and Elizabeth A. Archie 


\title{
Multi-scale predictors of parasite risk in wild male savanna baboons (Papio cynocephalus)
}

\author{
Bobby Habig $^{1,2}$ (D) David A. W. A. M. Jansen ${ }^{1}$ - Mercy Y. Akinyi ${ }^{3,4} \cdot$ Laurence R. Gesquiere $^{3} \cdot$ Susan C. Alberts ${ }^{3,4}$. \\ Elizabeth A. Archie ${ }^{1,4}$
}

Received: 6 April 2019 /Revised: 20 August 2019 / Accepted: 29 August 2019

(C) Springer-Verlag GmbH Germany, part of Springer Nature 2019

\begin{abstract}
Several factors are thought to shape male parasite risk in polygynous and polygynandrous mammals, including male-male competition, investment in potentially immunosuppressive hormones, and dispersal. Parasitism is also driven by processes occurring at larger scales, including host social groups and populations. To date, studies that test parasite-related costs of male behavior at all three scales—individual hosts, social groups, and the host population-remain rare. To fill this gap, we investigated multi-scale predictors of helminth parasitism in 97 male savanna baboons (Papio cynocephalus) living in the Amboseli ecosystem in Kenya over a 5-year span. Controlling for multi-scale processes, we found that many of the classic indicators of male mating effort—high dominance rank, testosterone, and glucocorticoids — did not predict helminth infection risk. However, we identified two parasite-related costs associated with male behavior: (i) socially connected males exhibited higher Trichuris trichiura egg counts and greater parasite species richness than socially isolated males and (ii) males with stable group residency exhibited higher parasite species richness than males who frequently dispersed to new social groups. At the population level, males harbored more parasites following periods of drought than rainfall. Lastly, parasites exhibited positive covariance suggesting that infection risk increases if a host already harbors one or more parasite taxa. These results indicate that multi-scale processes are important in driving male parasite risk and that some aspects of male behavior are costly. Together, our results provide an unusually holistic perspective on the drivers of parasite risk in the context of male behaviors and life histories.
\end{abstract}

\section{Significance statement}

Infection by gastrointestinal helminths can have major consequences for host fitness, especially in the context of male mating effort. Multi-scale processes - from the host to its social group and population - are important for understanding key drivers of parasitism. We leveraged long-term data from one of the longest running behavioral ecology studies of a wild primate population in the world, the well-studied Amboseli baboon population in Kenya. We found that traditional indicators of male mating effort (attaining high dominance rank, high testosterone and glucocorticoids) did not predict parasitism. However, male social connectedness to females, competitive group demography, and harsh weather were all associated with higher parasitism. Because socially connected males faced the highest parasite risk, males may face a tradeoff between male-female relationships and parasitism. Our results show how processes at multiple scales contribute to variation in male parasite risk.

Communicated by D. P. Watts

Electronic supplementary material The online version of this article (https://doi.org/10.1007/s00265-019-2748-y) contains supplementary material, which is available to authorized users.

Bobby Habig

rhabig@nd.edu

1 Department of Biological Sciences, University of Notre Dame, Galvin Life Sciences Building, Notre Dame, IN 46556, USA
2 Present address: Department of Biology, Queens College, City University of New York, 65-30 Kissena Blvd., Flushing, New York, NY 11367, USA

3 Departments of Biology and Evolutionary Anthropology, Duke University, Box 90338, Durham, NC 90338, USA

4 Institute of Primate Research, National Museums of Kenya, Nairobi, Kenya 
Keywords Dominance rank · Glucocorticoids · Papio cynocephalus · Parasitism · Social connectedness · Testosterone

\section{Introduction}

Helminth parasites can have major consequences for host fitness and health, by reducing host fecundity (e.g., Budischak et al. 2017; Akinyi 2019), decreasing survival (e.g., Schneider-Crease et al. 2017), and increasing susceptibility to infection by other parasites (e.g., Ezenwa et al. 2010). These costs are especially important in the context of male behavior and life histories because male reproductive effort should have major consequences for individual infection risk (Lee 2006). Indeed, in polygynous and polygynandrous mammals, males face higher susceptibility and/or exposure to parasites as a result of the high energetic costs of male-male contest competition for mates, high rates of physical contact with female mates and male combatants, and high levels of potentially immunosuppressive steroid hormones that support male mating effort (Muehlenbein and Bribiescas 2005; Lee 2006; Creel et al. 2013). However, heterogeneities in individual parasite risk are driven not only by these host-level processes, but also by processes at higher scales, including those operating at the level of host social groups and populations (Fig. 1). To our knowledge, only one other study has tested parasite-related costs of male behavior in this holistic context (Arlet et al. 2015). Importantly, discovering the drivers of male infection risk in natural populations is essential both for population management and for understanding the basic ecology of infectious disease. Specifically, identifying key drivers of parasitism is necessary to reveal the selection pressures that shape host life histories, identify which hosts are most at risk, and pinpoint which hosts are the dominant drivers of parasite transmission.

Several previous studies find that aspects of male life histories and behavior shape parasite risk in mammals (e.g., Müller-Graf et al. 1996; Negro et al. 2010; Arlet et al. 2015). For instance, male-male contest competition for mates requires males to invest in muscle mass, large body size, and other expensive sexually selected traits and ornaments (Darwin 1871; Andersson 1994; Clutton-Brock 2007). These traits often correlate with parasite risk (Hamilton and Zuk 1982; Moller et al. 1999; Coulson et al. 2018). Competing males also fight with other males to climb dominance hierarchies, exclude other males from breeding territories, or guard female mates (Alberts et al. 1996; Ezenwa 2004). These investments are energetically costly, potentially creating tradeoffs with maintenance-related traits, including immune function (Lee 2006; Habig and Archie 2015). Furthermore, many of these activities involve high rates of contact with conspecifics, including male competitors or female mating partners, which in turn may increase parasite exposure (Altizer et al. 2003; Lee 2006; Fairbanks and Hawley 2012; Habig et al. 2018). In mammals, males are often the dispersing sex (Prugnolle and de Meeus 2002), and dispersal may also influence parasite risk because transferring to another group carries energetic costs (Bonte et al. 2012).
Fig. 1 Population-, group-, and host-level processes that are thought to drive inter-host variation in helminth infection risk in male baboons. These hierarchical processes are indicated by concentric circles

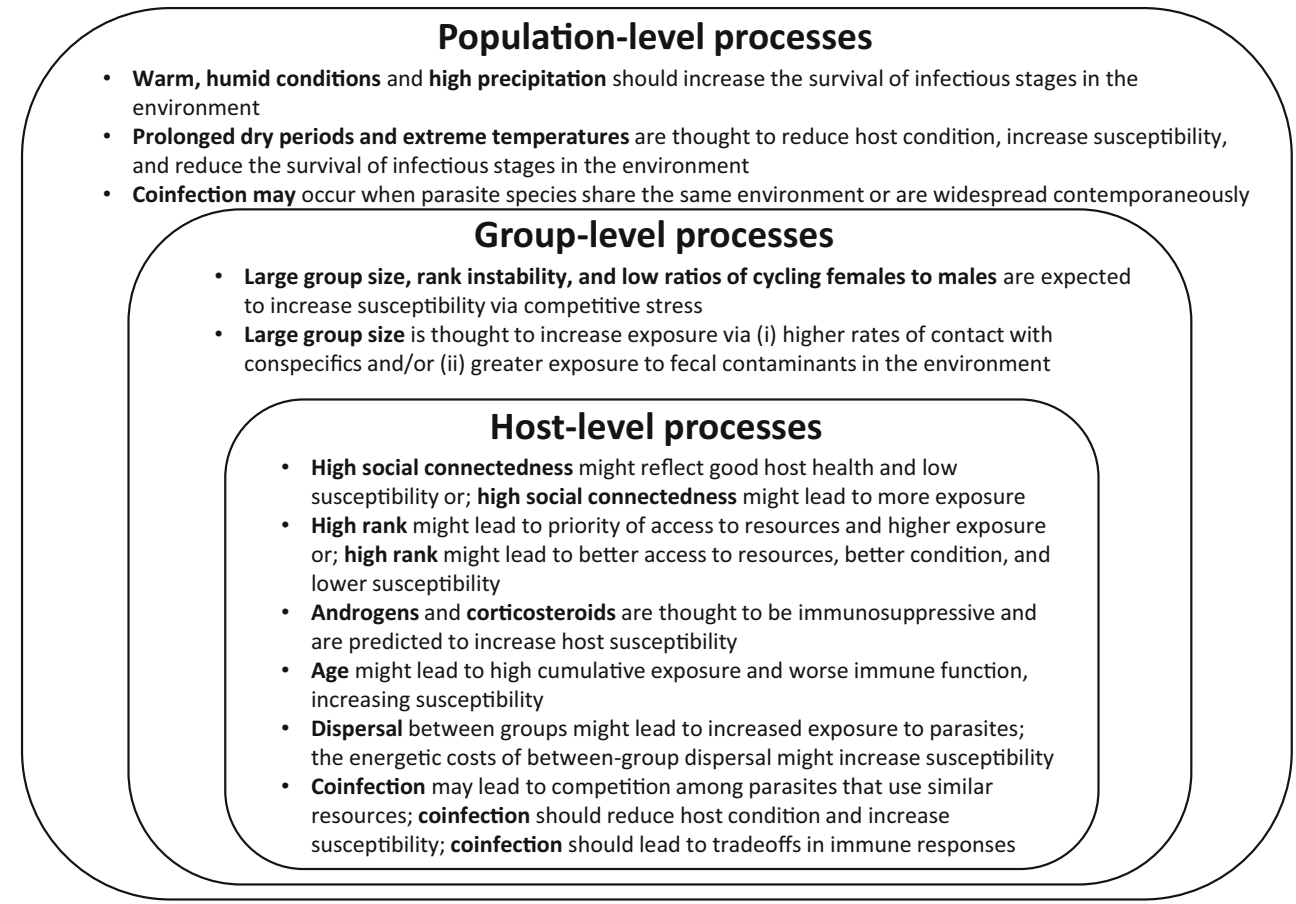


Further, because dispersing males move through new habitats or encounter new individuals, they may also encounter new infectious agents (Altizer et al. 2003; Nunn and Altizer 2006). Finally, all of these activities - from investment in secondary sexual characteristics to natal dispersal - are supported by steroid hormones, especially testosterone and glucocorticoids, which may be immunosuppressive in their own right (Folstad and Karter 1992; Nava-Castro et al. 2011). Hence, male mating effort may have myriad effects on male parasite risk.

Beyond the costs of mating effort (a host level process), processes operating at the level of the social group may also shape parasite risk in male mammals (Nunn and Altizer 2006). For instance, males who live in crowded conditions (i.e., large social groups), reproductively competitive social groups, and unstable hierarchies may be both more exposed and more susceptible to parasites than males who live in less crowded conditions, with fewer competitors, and in stable hierarchies. In support, a recent meta-analysis found consistent, positive associations between group size and both parasite intensity and prevalence (Patterson and Ruckstuhl 2013; but see Rifkin et al. 2012). These results were attributed to both patterns of exposure (increased contact rates among hosts in larger groups) and susceptibility (nutritional limitation and competitive stress associated with living in a more densely populated environment). Whether similar processes occur as a result of inter-group variation in competitive conditions and rank stability remains unknown.

Processes that occur at the level of the entire host population-especially the abiotic environment-can also drive parasite exposure and susceptibility. In terms of exposure, ambient temperature and precipitation may affect the survival of parasite infectious stages that are transmitted through the environment (Nunn and Altizer 2006). For instance, hosts living in warm, humid conditions with moderate temperatures are expected to experience higher parasite exposure than hosts in low rainfall environments with more extreme temperatures (e.g., Bucknell et al. 1995; Atherholt et al. 1998; Guernier et al. 2004). In terms of susceptibility, periods of drought or extreme temperatures can reduce food availability, diet quality, and cause thermal stress in hosts, which may influence host susceptibility to infection (Nunn and Altizer 2006; Mignatti et al. 2016). Hence, individuals may exhibit the highest parasite loads at the end of a long dry season (e.g., Ezenwa 2004) or after periods of extreme temperatures (e.g., Meade 1983).

Finally, parasite infection rarely occurs in isolation, and wild animals are often infected with multiple parasite species simultaneously. These patterns of coinfection may be mediated by both population- and host-level processes (Graham 2008; Wilcox et al. 2015). On a population level, if two or more parasite species co-occur in the same environment and are widespread contemporaneously, then we expect these parasites to positively covary in hosts (Mwangi et al. 2006; Graham 2008). Conversely, if parasite species differ spatially or temporally in the environment, then we expect these parasites to negatively covary in hosts (Warburton et al. 2016). On a host level, positive covariance between parasites can arise when unhealthy individuals are exceptionally susceptible to parasitism or when infection with one parasite species compromises host immunity or damages host tissues, increasing infection risk with other parasite species (Ezenwa et al. 2010; Griffiths et al. 2011; Papier et al. 2014). Negative covariance between parasites can be driven by competitive exclusion or altered immune responses that reduce host susceptibility to other parasites (Holmes 1961; Jolles et al. 2008; Stancampiano et al. 2010). These population- and host-level processes may interact. For instance, if parasite taxa co-occur spatially and temporally in the environment during their infective stages (population-level process) and subsequently occupy similar niches in the gastrointestinal tract during their adult stages (host-level process), these taxa should negatively covary because they are competing for similar resources (Holmes 1961).

Our goal was to understand predictors of helminth parasitism in male baboons at multiple scales (Fig. 1; Table 1). To accomplish this goal, we leveraged the long-term, individualbased data collected by the Amboseli Baboon Research Project (ABRP) on male parasite burdens, dominance rank, social interactions, dispersal histories, and hormone levels, as well as group- and population-level information on social and abiotic environments (Alberts and Altmann 2012). This population is comprised primarily of yellow baboons (Papio cynocephalus) with some naturally occurring admixture from neighboring $P$. anubis baboon populations (hereafter called savanna baboons; Alberts and Altmann 2001; Tung et al. 2008). Savanna baboons are diurnal, semi-terrestrial primates that reside in multi-male, multi-female social groups; members of this species typically exhibit linear dominance hierarchies, strong sexual dimorphism, and intense male-male competition for reproductive opportunities (Hausfater 1975; Alberts et al. 2003; Gesquiere et al. 2011a). Males disperse following puberty and continue to transfer between groups throughout their lives, seeking mating opportunities (Alberts and Altmann 1995a). Access to mating opportunities is determined by male dominance rank, which is acquired through aggressive conflict with other males (Hausfater 1975; Alberts et al. 2003). Males attain their highest adult rank around age ten, after which rank declines with age (Alberts et al. 2003). High-ranking males typically exhibit higher testosterone and lower glucocorticoid concentrations than lowranking males, with one important exception: alpha males exhibit both high testosterone and high glucocorticoids (Gesquiere et al. 2011a).

Baboons in Amboseli are exposed to a diverse community of helminth parasites (Table S1). The four most common 
Table 1 Environmental, demographic, behavioral, endocrinological, and parasitological predictors of male parasite risk

Sample size $=652$ samples; 97 males unless otherwise noted

Random effects
Individual identity
Group identity
Observer
Response variables
Probability of $A$. caucasica infection
Probability of $S$. pigmentatus infection
Probability of strongyle infection
Log $T$. trichiura intensity
Parasite richness
Fixed effects
Individual age
Dominance rank
Number of social groups
Consecutive male residency
Group size
Rank stability

Sex ratio

Rainfall

Temperature

A. caucasica infection ${ }^{\mathrm{a}}$

S. pigmentatus infection ${ }^{\mathrm{a}}$

Strongyle infection ${ }^{\mathrm{a}}$

T. trichiura ${ }^{\text {a }}$

Social connectedness ${ }^{\mathrm{b}}$

Testosterone $^{\mathrm{b}}$

Glucocorticoids $^{\mathrm{b}}$
The identity of the subject contributing to the sample

The identity of the group the subject resided in

The identity of the researcher who counted the parasites

Presence or absence of A. caucasica in a given sample

Presence of absence of $S$. pigmentatus in a given sample

Presence of absence of strongyles in a given sample

Number of T. trichiura eggs identified in a host sample (log-transformed)

Number of distinct parasite taxa identified in a given sample

Age in years of the subject when the sample was collected; continuous

Ordinal rank of the individual male during month of sample collection

Number of social groups an individual male lived in the year before the date of sample collection

The number of consecutive days a male lived in a social group prior to the date of sample collection.

Mean number of adult males and females residing in the group during the month of sample collection; continuous

Stable: No change in alpha, beta, or gamma rank in the month before, during, or after sample collection; Unstable: Change in alpha, beta, or gamma rank in the month before, during, or after sample collection

Mean ratio of cycling females to adult males during the month of sample collection

Total amount of rainfall (in $\mathrm{mm}$ ) in the 3 months before sample collection

Mean daily maximum temperature $\left({ }^{\circ} \mathrm{C}\right)$ in the 3 months before sample collection

Presence or absence of $A$. caucasica in a given sample

Presence or absence of $S$. pigmentatus in a given sample

Presence or absence of strongyles in a given sample

Number of T. trichiura eggs identified in a host sample

Amount of grooming a male received from and delivered to adult females, relative to all other males in the population in the same year and controlled for observer effort.

Social connectedness is calculated in the 12 months before sample collection.

Mean fecal testosterone ( $\mathrm{ng} / \mathrm{g}$ ) levels during month of sample collection

Mean fecal glucocorticoid (ng/g) levels during month of sample collection

${ }^{a}$ The presence or intensity of a parasite was not modeled as a predictor variable in cases where the parasite itself was modeled as the response variable

${ }^{\mathrm{b}}$ For social connectedness, testosterone, and glucocorticoids, we ran subset models where we tested whether the addition of any of these covariates significantly improved the best-supported main models ( $n=545$ samples; 91 males)

parasites are whipworms (Trichuris trichiura), strongyles (i.e., members of the family Strongylidae, which produce morphologically similar eggs), and two species of stomach worms (Abbreviata caucasica and Streptopharagus pigmentatus) (Hausfater and Watson 1976; Meade 1983; Hahn et al. 2003; Akinyi et al. 2019). Both whipworms and strongyles are transmitted via ingestion of an infective egg or larvae residing on food or surfaces in the host's environment. The two stomach worms-A. caucasica and S. pigmentatus-are transmitted via ingestion of an intermediate arthropod host. Importantly, many of these parasites are costly to baboons (Table S1): Baboons infected with A. caucasica and S. pigmentatus have been observed with adult worms hooked to the mucosal lining of their stomachs causing ulcers, damage to the mucosal lining, and inflammation (Pettifer 1984). Baboons infected with strongyles and T. trichiura have been observed with tarry black nodules in their large intestines; heavy infestation is associated with ulceration, weight loss, diarrhea, and increased risk of mortality (Pettifer 1984; Strait et al. 2012). Moreover, in Amboseli, female baboons who exhibit high parasite richness have low fertility, and high T. trichiura egg counts were linked to elevated glucocorticoid hormones in females (Akinyi et al. 2019). Our multi-dimensional data allowed us to test whether an unusually extensive range of behavioral, demographic, endocrinological, and environmental factors predict parasitism (for specific predictions, refer to 
Fig. 1). These data provide an unusually comprehensive exploration of the complex drivers of parasite risk in male mammals.

\section{Materials and methods}

\section{Study population and site}

Data were collected over a 5-year span as part of a long-term study of savanna baboons (Papio cynocephalus) from the Amboseli ecosystem in East Africa $\left(2^{\circ} 40^{\prime} \mathrm{S}, 37^{\circ} 15^{\prime} \mathrm{E}\right.$, $1100 \mathrm{~m}$ ) (Alberts and Altmann 2012). Amboseli is a semiarid savanna interspersed with grasses, sparse Acacia woodlands, and sporadic watering holes. Study subjects were wild, adult males $(n=97)$ residing in one of eleven social groups between March 2011 and September 2015; all males were individually recognizable based on unique morphological characteristics. Members of this population are wild-feeding, with no access to human-derived foods. ABRP researchers observe members of four to six social groups during 5-h monitoring visits, 6 days a week, year-round; each group is typically visited three or four times per week. It was not possible to record data blindly because our study involved focal animals in the field.

\section{Sample collection and parasitological analyses}

Parasite burdens were estimated by counting parasite eggs in fecal samples, which is an indirect, yet common measure of parasitism (Cabaret et al. 1998; Gassó et al. 2015; Byrne et al. 2018). Fecal egg counts are particularly necessary for measuring parasite burdens non-invasively, and several studies of mammals, including humans, have reported a positive correlation between adult worm burdens and fecal egg counts (e.g., Cabaret et al. 1998; Gassó et al. 2015; Byrne et al. 2018). However, possible limitations of this methodology are nonlinear relationships between worm infection intensity and egg shedding (Michael and Bundy 1989) and competitive interactions between parasites (Stancampiano et al. 2010).

Fecal samples were collected opportunistically during monitoring visits. A total of 652 fecal samples were collected from 97 male subjects (mean $=7$ samples/individual; range $=$ 1-25). Egg counts provide more accurate estimates of parasite burden when data from multiple fecal samples are combined; however, we found no qualitative differences in our results when we excluded males represented by a single fecal sample $(n=12)$; hence, our analyses include all samples. Samples were stored in $10 \%$ buffered formalin, and helminth ova were quantified via standardized methods for fecal flotation and sedimentation (Gillespie 2006; Bowman 2014). For each sample, two flotation slides were analyzed from a $4 \mathrm{~g}$ sample of fecal matter, and five sedimentation slides were analyzed from
$2 \mathrm{~g}$ of fecal matter (for detailed protocols, please refer to the Supplement).

Table S1 presents the life history traits and transmission strategies for the most common parasites we found. All of these taxa were previously known to infect baboons (Kuntz and Moore 1973; Hahn et al. 2003); many were observed in prior studies of this population (Hausfater and Watson 1976; Meade 1983; Hahn et al. 2003; Akinyi et al. 2019). In the current study, we focused on four taxa that had greater than $50 \%$ prevalence across males, and along with parasite species richness, these four were the focus of our analyses: (1) T. trichiura, (2) strongyles, (3) A. caucasica, and (4) S. pigmentatus. Note that "strongyles" refers to members of the family Strongylidae, whose members have eggs that are morphologically indistinguishable between different species (Müller-Graf et al. 1996; Arlet et al. 2015).

\section{Host-level predictors of parasitism}

We modeled several host-level predictors of male parasitism, including age, dispersal history, social interactions, steroid hormone concentrations, and the presence of infection with other parasites (Table 1).

Age Male ages originated from two sources: (i) $45.4 \%(n=44)$ of males were born into a study group, and we knew their birthdates within a few days; (ii) $54.6 \%(n=53)$ immigrated into the population after birth, and for these males, age was estimated within 1 to 2 years using a well-defined method that incorporates tooth wear, body size, coat condition, and body carriage (Alberts and Altmann 1995b). For all study subjects, the mean age was 12.82 years $(\mathrm{SD}=3.51$, range $=6.76$ 25.08 years, $n=97$ ).

Social factors Four aspects of males' social lives were included as predictor variables: (i) Male ordinal dominance ranks were constructed monthly based on wins and losses observed during agonistic interactions (Hausfater 1975). In this population, dominance rank relations are highly linear (Alberts et al. 2003; Gesquiere et al. 2011a; Archie et al. 2012). Therefore, the highest-ranking male was assigned a rank of 1 ; the secondranking male was assigned a rank of 2, and so on. (ii) Social connectedness to females was calculated using methods previously developed for female savanna baboons (Archie et al. 2014; Tung et al. 2016). We calculated a social connectedness index (SCI) for each male in each year of his life by quantifying the frequency with which the male received grooming from or delivered grooming to adult females, relative to all the other males in the population at the same time (Archie et al. 2014). Positive SCI values represent males with higher grooming frequencies; negative SCI values represent males with lower grooming frequencies. (iii) Number of social groups was calculated by summing the total number of social 
groups an individual male was observed living in during the year prior to the date of sample collection. The mean number of groups a male lived in the year prior to sample collection was 1.72 ( $\mathrm{SD}=1.03$, range $=1-7$ ). (iv) Consecutive male residency was calculated as the number of consecutive days a male lived in the social group in which the sample was collected prior to the date of sample collection. The mean consecutive male residency was 873.33 days $(\mathrm{SD}=923.96$, range $=2-5062)$.

Steroid hormone concentrations Two endocrinological predictors of parasite risk were included in our analyses: (i) fecal glucocorticoid concentrations (fGC) and (ii) fecal testosterone concentrations ( $f T$ ). Samples were assayed for fGC and fT by radioimmunoassay using well-established protocols as described in the Supplement (Gesquiere et al. 2008, 2011b, 2014; http://amboselibaboons.nd.edu/). The mean fGC concentration per sample was $75.20 \mathrm{ng} / \mathrm{g}(\mathrm{SD}=32.20$, range $=26.76-310.68)$; the mean $\mathrm{fT}$ concentration per sample was $84.27 \mathrm{ng} / \mathrm{g}(\mathrm{SD}=45.78$, range $=20.23-339.61)$. The same fecal samples were used for both hormone and parasitological analyses.

\section{Group-level predictors of parasitism}

Three group-level predictors of parasite risk were included in our models (Table 1). (i) Group size was known from neardaily censuses of the baboons in each social group and was calculated as the mean number of adults (males and females) living in the group in the month prior to sample collection. The mean group size was 59.25 adults $(\mathrm{SD}=21.75$, range $=$ 21-117). (ii) Rank stability was calculated following Gesquiere et al. (2011a). Briefly, social groups were "stable" if there was no change in alpha, beta, or gamma rank in the month before, during, or after sample collection and "unstable" if there was a change in alpha, beta, or gamma rank in the month before, during, or after sample collection. (iii) Sex ratio was calculated as the mean ratio of cycling (fertilizable) females to adult males during the month of sample collection. A social group was considered more reproductively competitive than another social group when there were fewer cycling females per adult male (Gesquiere et al. 2007). The mean ratio of cycling females to adult males during the study period was $0.54(\mathrm{SD}=0.30$; range $=0.16-4.07)$.

\section{Population-level predictors of parasitism}

We tested two population-level predictors of parasitism (Table 1). (i) Rainfall was collected using a rain gauge located at the field camp. We focused on the total amount of rainfall in the 3 months before sample collection because this time period predicts food availability and reflects many of the parasites' prepatent periods (Akinyi et al. 2019). During the study period, the mean total rainfall in the 3 -month periods before sample collection was $6.44 \mathrm{~cm}(\mathrm{SD}=6.61$; range $=0$ $26.15 \mathrm{~cm}$ ). (ii) Temperature data were collected using a min$\max$ thermometer located in the field camp. We focused on the mean maximum daily temperature in the 3-month periods before sample collection because high temperatures limit parasite survival in the environment and also increase host stress and susceptibility (Akinyi et al. 2019). During the study period, the mean maximum daily temperature in the 3-month periods before sample collection was $32.21^{\circ} \mathrm{C}(\mathrm{SD}=1.47$; range 29.85 to $35.49^{\circ} \mathrm{C}$ ).

\section{Measures of parasitism and statistical analyses}

All statistical analyses were conducted in R ( $\mathrm{R}$ Core Team 2017). We used a mixed modeling approach to test predictors of five measures of parasitism: (i) $\log$ transformed $(\log +0.5)$ T. trichiura egg counts; the presence or absence of eggs from (ii) A. caucasica, (iii) S. pigmentatus, and (iv) strongyles; and (v) parasite richness as the number of distinct parasite taxa observed in each sample. We used the presence or absence of eggs for A. caucasica, S. pigmentatus, and strongyles because the proportion of infected samples for these parasites was less than $75 \%$ (Table 2). We modeled T. trichiura using egg counts per total grams of sampled feces (hereafter called egg count) for T. trichiura because its eggs were exceptionally abundant, found in $96 \%$ of all samples with a median of 103 eggs per sample (range $=1-5957$ among infected samples). Both log-transformed T. trichiura intensity and parasite richness were modeled using Gaussian error distributions; measures of presence/absence were modeled using binomial error distributions.

Our response variables, fixed effects, and random effects are summarized in Table 1. All mixed models were performed using the packages lme4 (Bates et al. 2014) and lmerTest (Kuznetsova et al. 2015). To select the best fitting models, we used the step function in the lmerTest package (Kuznetsova et al. 2015), and we confirmed the best fitting models using log likelihood ratio tests. Because the use of stepwise fitting models in behavioral ecology research has been criticized for leading to inflated type 1 error rates (Mundry and Nunn 2009), we also performed multiple comparison tests of all possible model combinations using the package MuMIn (Bartoń 2009) and used Aikake information criterion (AIC) to weigh alternative models against each other (Burnham and Anderson 2004). Our models yielded the same results using both approaches.

Before performing our analyses, we checked for multicollinearity using a form of the variance inflation factor (VIF) analysis adapted for lmer models (A. Franks pers. comm.). These analyses indicated that we should remove both rank (correlated with age: $r=0.606, P<0.001, n=652$ ) and temperature (correlated with rainfall: $r=0.581, P<0.001, n=652$ ) from the models due to high levels of variance inflation (Belsley 1980). Because we still wanted to control for these variables, we conducted a simple linear regression of rank controlling for age and 
Table 2 Prevalence of infected individuals and the proportion and median egg count of infected samples

\begin{tabular}{lllc}
\hline Parasite & Prevalence of infected males $(n=97)$ & Proportion of infected samples $(n=652)$ & Median intensity (range in parentheses) \\
\hline Trichuris trichiura & $100 \%(n=97)$ & $96.0 \%(n=625)$ & $103.0(1-5957)$ \\
Strongyles & $96.9 \%(n=94)$ & $73.0 \%(n=476)$ & $3.0(1-70)$ \\
Abbreviata caucasica & $81.4 \%(n=79)$ & $41.1 \%(n=268)$ & $3.0(1-93)$ \\
Streptopharagus & $56.7 \%(n=55)$ & $22.2 \%(n=145)$ & $2.0(1-50)$ \\
$\quad$ pigmentatus & $14.4 \%(n=14)$ & $3.5 \%(n=23)$ & $2.0(1-767)$ \\
Enterobius vermicularis & $8.2 \%(n=8)$ & $1.5 \%(n=10)$ & $1.5(1-18)$ \\
Strongyloides fuelleborni & $7.2 \%(n=7)$ & $1.1 \%(n=7)$ & $3.0(1-2)$ \\
Acanthocephala & $3.1 \%(n=3)$ & $0.4 \%(n=3)$ & $9.5(1-18)$ \\
Primasubulura & $2.1 \%(n=2)$ & $0.3 \%(n=2)$ & \\
Trematoda spp. & &
\end{tabular}

temperature controlling for rainfall and then incorporated the residuals of rank and temperature into our models (e.g., Graham 2003; Dormann et al. 2013). The rank residuals are positive when male rank was high for a given age, and negative when male rank was low for a given age. Likewise, the temperature residuals indicate when temperatures were high (positive) or low (negative) for a given amount of rainfall.

Three of the fixed effects of interest (fGC, fT, and social connectedness) had missing data. Therefore, we performed two sets of models. The first set tested predictors of parasitism in all samples ( $n=652$ samples from 97 males). The fixed effects in these models included the following: age, residuals of dominance rank controlling for age, dispersal covariates (number of groups; consecutive male residency), the presence of other helminths, group size, rank stability, sex ratio, rainfall, and the residuals of temperature controlling for rainfall. The second set of models tested the three additional variables (fGC, fT, and social connectedness) in the subset of the data for which information on these variables was available ( $n=545$ samples from 91 males). For each of these three predictor variables, we tested (via likelihood ratio tests) whether adding the predictor significantly improved the best-supported model from the larger dataset. If none of these predictors improved model fit, then we present the results from the larger dataset of 652 samples from 97 males; this was the case for A. caucasica, S. pigmentatus, and strongyles. If the addition of one or more of these fixed effects significantly improved model fit, then we present the model results using the reduced dataset of 545 samples from 91 males; this was the case for T. trichiura egg counts and parasite richness.

\section{Results}

\section{Helminth parasite species, prevalence, and abundance}

We identified nine helminth taxa in our study population, which varied in their prevalence and intensity (Table 2). The most common parasite was T. trichiura, followed by strongyles, A. caucasica, and S. pigmentatus. The number of parasite taxa per sample ranged from 0 to 6 (Fig. 2); the median parasite richness in each sample was two taxa. All males (100\%) harbored one or more parasite taxa across all their samples; at least one parasite was identified in $98.5 \%$ of the samples.

\section{Host-level processes: male social connectedness predicts parasite risk}

Only one host-level trait was linked to male mating effort: male social connectedness with females predicted male parasite risk (Table 3). Specifically, males with higher social connectedness exhibited higher T. trichiura egg counts and higher parasite richness than socially isolated males (T. trichiura: estimate $=0.113, P<0.001$; richness: estimate $=0.117, P=$ 0.002; Fig. 3a; Table 3). Holding other predictors at their median values, males in the top third of SCI exhibited $23.3 \%$ higher parasite richness than males in the bottom third.

Other host-level factors linked to male mating effortspecifically dominance rank and steroid hormone concentrations - either were not significantly associated with parasite risk (e.g., rank) or were associated, but in an unexpected direction (e.g., glucocorticoids). In male baboons, dominance rank and age are correlated such that young adults tend to be high-ranking and the oldest males tend to be lowranking (Alberts et al. 2003). While male age was a significant predictor of two types of parasite risk (infection with T. trichiura and A. caucasica; Table 3), male dominance rank was not a significant predictor of any measure of male parasite risk when age was included the model (Table S2). Specifically, older males exhibited significantly higher T. trichiura egg counts but lower risk of $A$. caucasica infection than younger males (Table 3: T. trichiura: estimate $=0.072$, $P<0.001$; Fig. 3b; . caucasica: estimate $=-0.073, P=$ $0.028)$. Notably, samples from 20 -year-old males harbored 1228 more $T$. trichiura eggs than samples from 10-year-old 


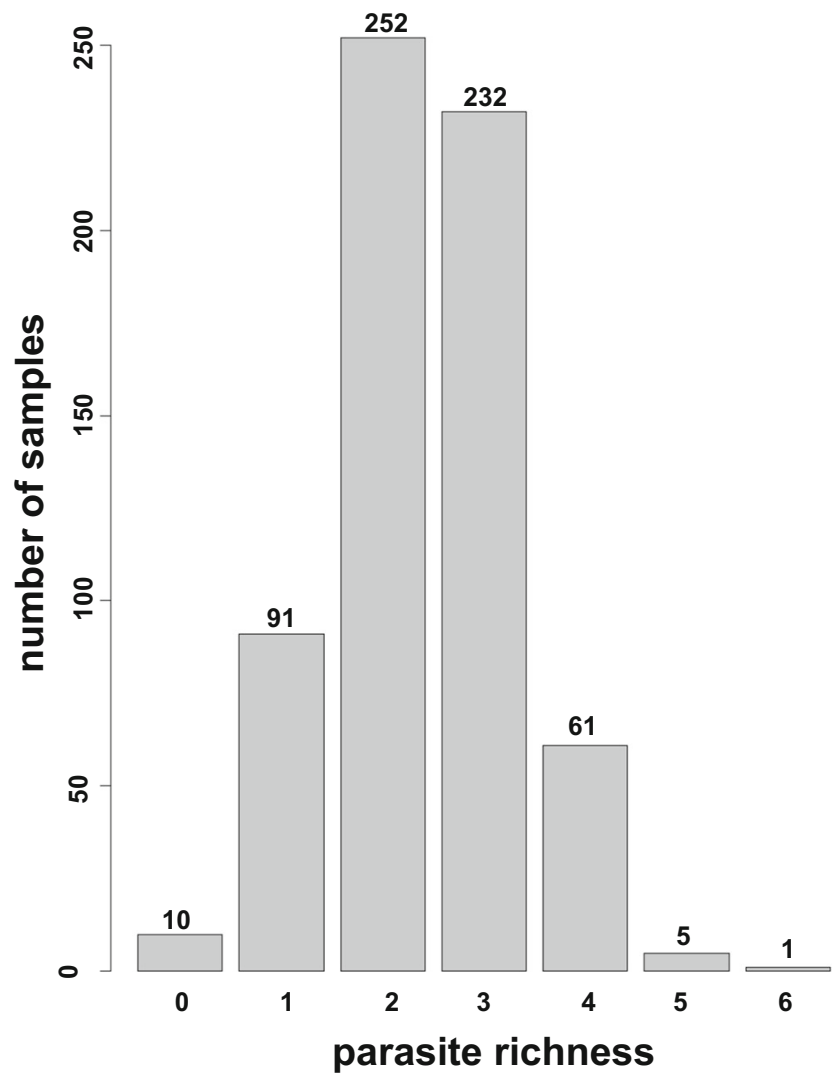

Fig. 2 Histogram of parasite richness across the 652 samples in our dataset

males, holding other predictors at their median values. We found little evidence that steroid hormones were associated with higher parasite risk. Contrary to our predictions, males with higher $\log$ fGC concentrations exhibited significantly lower T. trichiura egg counts than males with lower log fGC concentrations (estimate $=-0.451, P=0.015$; Fig. 3c; Table 3). We did not observe any significant associations between fT concentrations and measures of parasitism.

Contrary to the prediction that dispersal increases exposure to parasites, the number of groups a male lived in during the year prior to sample collection was negatively related to parasite risk: males who lived in more social groups exhibited lower parasite richness and lower risk of strongyle infection than males who lived in fewer groups (Table 3: richness: estimate $=-0.100, P=0.017$; strongyles: estimate $=-0.340$, $P=0.001$ ). In terms of consecutive male residency, we found no significant difference in parasitism between long-term and short-term residents.

\section{Group-level processes: sex ratio is associated with parasite risk}

We found mixed support for the idea that competitive demographic conditions within social groups are associated with elevated parasite burdens. In support, males in groups with fewer cycling females per adult male (presumed to indicate greater reproductive competition) harbored greater T. trichiura intensities than males in less competitive groups (estimate $=-0.542, P<0.001 ;$ Fig. 3d; Table 3). Notably, our effect sizes indicated that samples from males residing in groups in the bottom tertile of cycling females to adult males harbored approximately 194 more $T$. trichiura eggs on average than samples from males in the highest tertile, holding other predictors at their median values. However, for strongyles, males in social groups with more cycling females per adult male (presumed to indicate less intense competition) were more likely to be infected than males in groups with lower sex ratios (estimate $=1.123 ; P=0.028$; Table 3 ). We did not observe significant associations between group size or rank stability and parasitism.

\section{Population-level processes: males exhibited the highest parasite burdens during dry months}

For four of five measures of parasitism, we found that males exhibited the highest parasite burdens following dry months. Specifically, following dry periods, males exhibited significantly higher parasite richness, $T$. trichiura intensities, and risk of strongyles and A. caucasica infection (Table 3: A. caucasica: estimate $=-0.047, P=0.002$; richness: estimate $=-0.019, P<0.001 ;$ strongyles: estimate $=-0.033$, $P=0.042 ;$ T. trichiura: estimate $=-0.031, P<0.001$; Fig. $3 e)$. Notably, our effect sizes indicated that samples from males that experienced 3 months without rainfall had 119 more T. trichiura eggs on average than samples from males experiencing high rainfall $(\geq 10 \mathrm{~cm})$ in the prior 3 months, holding other predictors at their median values. However, males were more likely to be infected with $S$. pigmentatus following rainy periods (estimate $=0.051, P=0.003$; Table 3 ).

\section{Several parasite taxa exhibited positive covariance}

For all four common parasite taxa, infection intensity or risk was predicted by one or more other parasites. Samples that contained strongyles and A. caucasica had significantly higher $T$. trichiura egg counts (Fig. 3f, g; Table 3). Under median conditions, samples with strongyles and A. caucasica harbored on average 253 and 124 more T. trichiura eggs respectively than uninfected samples. Likewise, strongyle infection risk was predicted by T. trichiura; A. caucasica infection was predicted by S. pigmentatus and T. trichiura; and S. pigmentatus infection was predicted by A. caucasica infection (Table 3). For the two stomach worms - A. caucasica and S. pigmentatus - we did not find evidence of competitive exclusion; instead, these two parasite taxa were positively correlated (Table 3 ). 
Table 3 Best supported models for each measure of parasite risk in male baboons. Sample sizes for strongyles, A. caucasica, and $S$. pigmentatus were $n=652$ samples from 97 males. For T. trichiura and parasite richness, the addition of social connectedness and/or fGC improved model fit; these models were run on a smaller dataset with complete information on all covariates ( $n=545$ samples from 91 males). Best supported models were selected using log likelihood ratio tests

\begin{tabular}{|c|c|c|c|c|c|c|c|}
\hline Helminth taxa & Fixed effects & Process level & Estimate & $\mathrm{SE}$ & $t$ value & $P$ & Direction \\
\hline \multirow[t]{7}{*}{ T. trichiura } & Social connectedness & Host & 0.113 & 0.030 & 3.746 & $<0.001$ & $\uparrow \mathrm{SCI}, \uparrow T$. trichiura \\
\hline & Age & Host & 0.072 & 0.013 & 5.500 & $<0.001$ & $\uparrow$ Age, $\uparrow T$. trichiura \\
\hline & Glucocorticoids (fGC) & Host & -0.451 & 0.184 & -2.445 & 0.015 & $\uparrow$ Glucocorticoids, $\downarrow$ T. trichiura \\
\hline & Strongyles & Host/population & 0.221 & 0.061 & 3.624 & $<0.001$ & $\uparrow$ Strongyles, $\uparrow$ T. trichiura \\
\hline & A. caucasica & Host/population & 0.149 & 0.055 & 2.727 & 0.007 & $\uparrow A$. caucasica,$\uparrow T$. trichiura \\
\hline & Sex ratio & Group & -0.542 & 0.100 & -5.433 & $<0.001$ & $\uparrow \mathrm{F}: \mathrm{M}$ sex ratio, $\downarrow$ T. trichiura \\
\hline & Rainfall (cm) & Population & -0.031 & 0.004 & -7.358 & $<0.001$ & $\uparrow$ Rainfall, $\downarrow$ T. trichiura \\
\hline \multirow[t]{4}{*}{ Strongyles } & Number of groups & Host & -0.340 & 0.105 & -3.255 & 0.001 & $\uparrow$ Number of groups, $\downarrow$ strongyles \\
\hline & T. trichiura & Host/population & 0.544 & 0.141 & 3.865 & $<0.001$ & $\uparrow T$. trichiura, $\uparrow$ strongyles \\
\hline & Sex ratio & Group & 1.123 & 0.512 & 2.192 & 0.028 & $\uparrow \mathrm{F}: \mathrm{M}$ sex ratio, $\uparrow$ strongyles \\
\hline & Rainfall (cm) & Population & -0.033 & 0.016 & -2.037 & 0.042 & $\uparrow$ Rainfall, $\downarrow$ T. trichiura \\
\hline \multirow[t]{4}{*}{ A. caucasica } & Age & Host & -0.073 & 0.033 & -2.200 & 0.028 & $\uparrow$ Age, $\downarrow$ A. caucasica \\
\hline & T. trichiura & Host/population & 0.506 & 0.137 & 3.701 & $<0.001$ & $\uparrow T$. trichiura, $\uparrow A$. caucasica \\
\hline & S. pigmentatus & Host/population & 0.531 & 0.218 & 2.433 & 0.015 & $\uparrow S$. pigmentatus, $\uparrow A$. caucasica \\
\hline & Rainfall (cm) & Population & -0.047 & 0.015 & -3.032 & 0.002 & $\uparrow$ Rainfall, $\downarrow$ A. caucasica \\
\hline \multirow[t]{3}{*}{ S. pigmentatus } & A. caucasica & Host/population & 0.576 & 0.225 & 2.554 & 0.011 & $\uparrow A$. caucasica $=\uparrow S$. pigmentatus \\
\hline & Rainfall (cm) & Population & 0.051 & 0.017 & 3.012 & 0.003 & $\uparrow$ Rainfall= $\uparrow S$. pigmentatus \\
\hline & Temperature residuals & Population & 0.229 & 0.098 & 2.336 & 0.020 & $\uparrow$ Temperature, $\uparrow S$. pigmentatus \\
\hline \multirow[t]{3}{*}{ Parasite richness } & Social connectedness & Host & 0.117 & 0.037 & 3.129 & 0.002 & $\uparrow \mathrm{SCI}, \uparrow$ richness \\
\hline & Number of groups & Host & -0.100 & 0.042 & -2.395 & 0.017 & $\uparrow$ Number of groups, $\downarrow$ richness \\
\hline & Rainfall (cm) & Population & -0.019 & 0.006 & -3.358 & $<0.001$ & $\uparrow$ Rainfall, $\downarrow$ richness \\
\hline
\end{tabular}

\section{Discussion}

In Amboseli, male baboons varied in parasite richness and helminth infection intensity; these differences were attributed to host-, group-, and population-level processes (Fig. 1). Previous studies of disease risk in male mammals have largely focused on processes occurring at one or two of these hierarchical levels (e.g., Hausfater and Watson 1976; Müller-Graf et al. 1996; Leclaire and Faulkner 2014). When we controlled for multi-scale processes, some of the traditional predictors linked to male mating effort, namely male dominance rank and steroid hormone concentrations, were generally not significant drivers of parasitism. However, we did identify one potentially costly aspect of male mating effort: social contact with females. Males who had more frequent grooming interactions with females exhibited higher T. trichiura egg counts and parasite species richness than socially isolated males. Interestingly, males with high fGC concentrations harbored low quantities of $T$. trichiura eggs, suggesting that fGC expression indicates increased energetic expenditures associated with reproductive effort rather than poor health (Archie et al. 2012; Lea et al. 2018). We also found an apparent cost for males who do not disperse frequently. Specifically, even after controlling for age and rank, males who tended to reside in only one social group for an extended period of time were at higher risk of parasitism than males who resided in multiple social groups. At higher scales (group- and population-level processes), the ratio of cycling females to adult males and patterns of rainfall were also important predictors of parasite risk. Lastly, several parasites exhibited positive covariance suggesting that infection risk increases if a host already harbors one or more parasite taxa. Together, these results suggest that accounting for multi-scale processes is important for understanding the dominant drivers of parasitism in male primates.

\section{Male social connectedness to females was the costliest aspect of male mating effort}

Two mechanisms might explain the association we observed between social connectedness and parasitism: one mechanism driven by susceptibility and another driven by exposure (Fig. 1). Under the susceptibility-driven mechanism, social isolation is a sign of poor condition and health; hence, socially isolated males may exhibit the highest parasite burdens (Fairbanks and Hawley 2012; Habig et al. 2018). Under the 


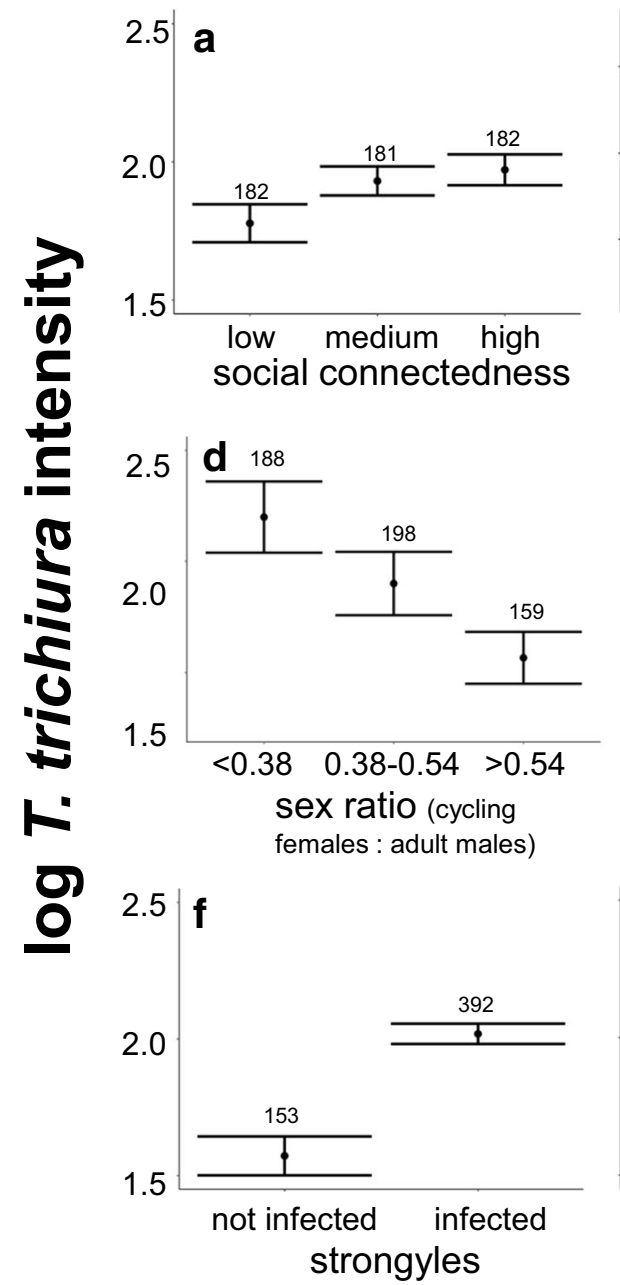

Fig. 3 Plots showing associations between $\log T$. trichiura intensity in male baboons and the fixed effects in Table 3. Plots are a social connectedness to adult females, $\mathbf{b}$ age (years), $\mathbf{c}$ fGC concentrations $(\mathrm{ng} / \mathrm{g})$, d ratio of cycling females to adult males, e rainfall $(\mathrm{cm}), \mathbf{f}$

exposure-driven mechanism, social contact serves as a conduit for the transmission of directly transmitted parasites, which may explain why socially connected males exhibited higher T. trichiura egg counts (Fairbanks and Hawley 2012; Habig et al. 2018). Moreover, socially connected males might have greater access to resources than less socially connected males, which also might increase exposure to parasites (e.g., Halvorsen 1986; Ezenwa 2004). Our results support the exposure-driven process, and together with other similar findings in vertebrates (e.g., meerkats, Suricata suricatta: Drewe 2010; Japanese macaques, Macaca fuscata: MacIntosh et al. 2012; spider monkeys, Ateles hybridus: Rimbach et al. 2015), these results suggest that parasite exposure is a cost of social contact.

However, none of the parasites in our analyses are known to be transmitted via direct contact (Table S1), raising the question: why do we see evidence of an exposure-driven process? One explanation is that residual fecal matter containing the eggs of T. trichiura may be carried in the animals' fur and

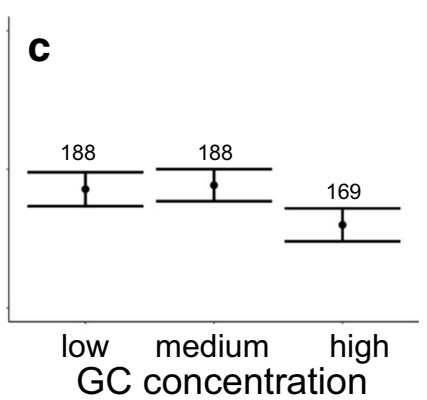

age (years)

GC concentration 
changes in susceptibility or exposure; in particular, higher parasite burdens with age may reflect both immunosenescence and the effects of cumulative, lifelong parasite exposure. In support, older, longer-lived adult hosts have been found to harbor more parasites than younger, shorter-lived adult hosts (e.g., savanna baboons, Papio cynocephalus: Hausfater and Watson 1976; freshwater fish: Bell and Burt 1991; wood mice, Apodemus sylvaticus: Behnke et al. 1999). The observation that young males are most infected with A. caucasica might result from age-related differences in exposure, for instance if younger males are more likely to forage on the arthropod vector of $A$. caucasica. At any rate, these age-related effects are also interesting in the context of male dominance rank. In baboons, as in many mammals in which rank is determined by strength and fighting ability, male rank is often tightly correlated with age: young, prime-age adults tend to be higher ranking than older males (Alberts et al. 2003). In our study, we did not find statistical evidence for an effect of dominance rank on male parasitism once we accounted for male age. Many previous studies of mammals have reported a significant association between dominance rank and parasitism (reviewed in Habig and Archie 2015; Habig et al. 2018). However, most of these studies were unable to statistically control for male age, which requires observing animals from birth, something logistically challenging in long-lived species with male-biased dispersal. Our results indicate that, without accounting for age, studies may overestimate or perhaps underestimate the relationship between dominance rank and parasitism in male mammals.

\section{Transient males harbor fewer parasites than sedentary males}

Contrary to our expectation that male dispersal is associated with parasite risk, we found that males who resided in more than one social group the year prior to sample collection harbored fewer parasites than males who resided in only one group. To our knowledge, no studies of vertebrates have assessed inter-individual differences in dispersal behavior in relation to parasitism. However, in comparative studies, migratory species experience higher parasite risk than sedentary species (Altizer et al. 2011), and species with large home ranges exhibit higher parasite richness than species with small home ranges (Altizer et al. 2003; Vitone et al. 2004; but see Nunn and Dokey 2006). Moreover, Arlet et al. (2015), in a study of gray-cheeked mangabeys (Lophocebus albigena), found that parasite incidence was greater in immigrant than resident males. Our data suggest three possible non-mutually exclusive hypotheses. First, dispersing males might spend more time isolated from conspecifics if they spend considerable time alone during dispersal, thus limiting parasite exposure (Alberts and Altmann 1995a). Second, males might be both socially and sexually isolated when newly immigrated into a group especially if they are rejected by other group members (which is often the case, and which often leads to these males dispersing repeatedly and more frequently than others) (Smith 1992), again limiting parasite exposure. Alternatively, because dispersal is energetically costly and dangerous, perhaps only males in relatively good physical condition take on the risk of between-group transfer (Clarke et al. 2008). Further studies are required to test these hypotheses.

\section{Group- and population-level processes}

On a group level, males in more competitive groups (i.e., fewer cycling females relative to adult males) exhibited greater T. trichiura intensities and lower strongyle risk than males in less competitive groups. These results, particularly the former finding, might reflect differences in competitive stress or male quality. For example, Gesquiere et al. (2007) found that competitive interactions among alpha males in this population peak when cycling females are sexually receptive. Moreover, across primates, there is considerable evidence that male-male competition is most intense when females honestly signal ovulation (reviewed in Nakahashi 2016). Whether the competitive stress associated with intense male-male competition during ovulation is a mechanism driving group-level differences in parasite risk remains an open question.

On a population level, precipitation patterns were significantly associated with parasite risk: males exhibited higher parasite richness, T. trichiura intensities, and risk of strongyles and $A$. caucasica infection following periods of low rainfall. This pattern is consistent with the hypothesis that long, dry periods reduce males' physical condition and increase susceptibility to infection. Furthermore, during the dry season, baboons in Amboseli increasingly rely on a small number of fecal-contaminated waterholes, which may increase exposure to parasitism. Strikingly, and in contrast to this pattern, most studies of African primates find that high rainfall is associated with higher parasitism (e.g., chimpanzees, Pan troglodytes: Huffman et al. 1997; Gillespie et al. 2010; gorillas, Gorilla beringei beringei: Rothman et al. 2008; mandrills, Mandrillus sphinx: Setchell et al. 2007; black and white colobus, Colobus guereza: Chapman et al. 2010). Our results suggest that Amboseli's semi-arid ecosystem might have different effects on hosts than studies where hosts reside in rain forests or in mountainous environments. In support, a study of bovids in an environment similar to Amboseli (the semi-arid Mpala Research Center in Kenya) found a significant positive association between drought intensity and parasitism (Ezenwa 2004). Thus, in arid environments, parasite risk might be manifested mainly by susceptibility-driven mechanisms - e.g., inadequate nutrition and reduced ability to cope with infection-whereas in non-arid environments, parasite risk might be manifested mainly by exposure-driven mechanisms 
based on survival of parasite infectious stages (Nunn and Altizer 2006). One potential implication of this finding for primates and other mammals that live in arid environments or that experience seasonal extremes in precipitation is the impact of climate change on the transmission of parasites as such environments become drier or experience greater extremes in patterns of rainfall (Lafferty 2009).

\section{Parasites exhibit positive covariance}

One of the most important predictors of parasite risk was the presence of other parasite taxa. For instance, T. trichiura egg counts were higher in baboons that were also infected with strongyles and/or A. caucasica. Furthermore, baboon hosts were more likely to be infected with these three parasites during extended dry periods. Since individual baboons are in relatively poor condition during the dry season (Gesquiere et al. 2011b), hosts may have been more susceptible to coinfection during periods of low rainfall. Thus, positive covariance may reflect susceptibility-mediated processes as individuals infected by one parasite may be in worse condition and therefore more susceptible to infection by other parasites (Griffiths et al. 2011; Papier et al. 2014).

Interestingly, we found no evidence of parasite-parasite competition as none of the parasite taxa covaried negatively, which suggests the possibility that gastrointestinal parasites do not limit each other if the host is immunocompromised. However, this result was puzzling in the case of two of the parasites, A. caucasica and S. pigmentatus, because the adult stages occupy the same environment (the stomach of the host baboon) and therefore may compete for living space. Further, A. caucasica was more abundant following high rainfall while $S$. pigmentatus was more abundant following low rainfall. Thus, based on one population-level process - i.e., parasites differing temporally in the environment (Pedersen and Fenton 2007; Warburton et al. 2016) and one host-level process - i.e., the presence of one parasite in the host precluding the presence of the other if both parasites are competing for similar resources (Holmes 1961; Larsen et al. 1991; Stancampiano et al. 2010), we expected A. caucasica and S. pigmentatus to covary negatively. Instead, we observed the opposite result: The presence of $A$. caucasica was positively associated with the presence of $S$. pigmentatus and vice versa. These findings were in contrast to a previous study of chacma baboons (Papio ursinus) in Kruger National Park, which reported that high infestation with one of these species corresponded with low infestation in the other species (Pettifer 1984). While we are unsure why these two species did not covary negatively in this population, one possibility is that the density of these parasites may not be high enough for competitive exclusion to occur in the stomachs of baboons. Alternatively, tissue damage in the stomach by one parasite may increase the likelihood of infection by the other (Ezenwa et al. 2010; Telfer et al. 2010). Furthermore, these two parasites are transmitted by insect vectors, and it may be that environmental or behavioral factors linked to the consumption of insects promote infection with both A. caucasica and S. pigmentatus.

\section{Conclusions and future directions}

Overall, our results illustrate the importance of integrating processes at multiple scales to better understand consequences for parasitism. At a host level, our study revealed that both social connectedness and patterns of dispersal are significantly associated with parasite risk. As there is emerging evidence in the vertebrate literature that males with high measures of social connectedness have a higher probability of reproductive success than socially isolated males (e.g., bottlenose dolphins, Tursiops aduncus: Connor et al. 2001; long-tailed manakin, Chiroxiphia linearis: McDonald 2007; Assamese macaque, Macaca assamensis: Schülke et al. 2010), one implication that can be elicited from our results is that socially connected males might tradeoff parasite risk for reproductive success. In terms of male dispersal, to our knowledge, this was the first study to assess inter-individual differences in dispersal behaviors in relation to parasitism. Our finding that males who tended to reside in only one social group for an extended period of time were at higher risk of parasitism suggests that there might be a cost for dispersing less frequently. Based on these two results, we recommend that future animal studies assess the interactions between social connectedness, dispersal, parasitism, and reproductive success across different taxa.

Our study also revealed the importance of accounting for multi-scale processes when studying the dominant drivers of parasite risk. In the present study, some aspects of male mating effort, including dominance rank and steroid hormone concentrations, were not correlated with parasite burdens after accounting for other male traits, and group- and populationlevel processes. Importantly, we found that without accounting for age, animal studies might be overestimating or underestimating the association between dominance rank and parasitism. Thus, our results highlight the need for additional studies to incorporate multi-scale processes to better understand the drivers of infection risk in animals.

In terms of group- and population-level processes, our finding that reproductively competitive groups exhibited higher T. trichiura intensities than less competitive groups, suggest that future animal studies should explore whether the competitive stress associated with intense male-male competition during ovulation drives variation in parasite risk. Moreover, because our data suggest that on a population level, arid ecosystems might be associated with increased risk of parasitism, we recommend additional animal studies in these types of environments especially in the context of climate change. Lastly, we found that if a male is infected with one parasite, he is likely to be infected with another parasite. Indeed, $84.5 \%$ of 
samples exhibited coinfection (infection with two or more helminth taxa) (Fig. 2). Therefore, we recommend that future studies not only examine patterns of coinfection among helminths, but also incorporate other parasite taxa including eukaryotic microparasites, prokaryotic parasites, and viruses (Graham 2008).

We think that the next critical step for behavioral ecologists who study parasitism is to test how multi-scale processes impact host survival and fitness. For example, we now know that female baboons living in the same population as the males of this study have shorter interbirth intervals (a proxy for lifetime reproductive success) when they exhibit higher helminth egg counts and parasite richness (Akinyi et al. 2019). We recommend that future studies in natural populations include controlled field experiments where a randomized set of subjects is administered anthelmintics, and subjects are followed to observe differences in rank, reproduction, or survival (e.g., African buffalo, Syncerus caffer: Ezenwa and Jolles 2015; Budischak et al. 2017). When experimental intervention is not feasible, we recommend observational survival analyses to test whether differences in parasitism predict mortality risk (e.g., gelada, Theropithecus gelada: Schneider-Crease et al. 2017). Thus, future studies that incorporate longitudinal, multivariate, experimental, and taxonomically diverse approaches will help to further enhance our understanding of host-host, host-parasite, and parasite-parasite dynamics and their impacts on host survival and Darwinian fitness.

Acknowledgments We gratefully acknowledge Kenya Wildlife Services, Institute of Primate Research, National Museums of Kenya, National Council for Science and Technology, and members of the AmboseliLongido pastoralist communities for their cooperation and assistance. We are grateful to Jeanne Altmann for her leadership and collaboration in producing behavioral and demographic data on the Amboseli baboons. The ABRP field team (R.S. Mututua, S. Sayialel, and J.K. Warutere) provided expert assistance with data collection; T. Wango and V. Oudo provided assistance with fecal sample processing. We also thank N. Learn, J. Gordon, and K. Pinc for database design and management. For a complete set of acknowledgments of funding sources, logistical assistance, and data collection and management, please visit http:// amboselibaboons.nd.edu/acknowledgements/. We would also like to thank David P. Watts, Justin Wilcox, and an anonymous reviewer for providing commentary on previous drafts of this manuscript.

Funding information This research was supported by the National Science Foundation and the National Institute on Aging, currently through NSF IOS 1456832 and through NIH R01AG053330, R01HD088558, and P01AG031719.

Data availability The datasets generated during the current study are available from the corresponding author on reasonable request.

\section{Compliance with ethical standards}

Ethical standards All applicable international, national, and/or institutional guidelines for the care and use of animals were followed. All protocols were approved by the Institutional Animal Care and Use
Committees at Duke University (A0840903) and the University of Notre Dame (13-11-1352).

Conflict of interest The authors declare that they have no conflict of interest.

\section{References}

Akinyi MY, Jansen D, Habig B, Gesquiere LR, Alberts SC, Archie EA (2019) Costs and drivers of helminth parasite infection in wild female baboons. J Anim Ecol 88:1029-1043. https://doi.org/10.1111/ 1365-2656.12994

Alberts SC, Altmann J (1995a) Balancing costs and opportunities: dispersal in male baboons. Am Nat 145:279-306. https://doi.org/10. $1086 / 285740$

Alberts SC, Altmann J (1995b) Preparation and activation - determinants of age at reproductive maturity in male baboons. Behav Ecol Sociobiol 36:397-406. https://doi.org/10.1007/bf00177335

Alberts SC, Altmann J (2001) Immigration and hybridization patterns of yellow and anubis baboons in and around Amboseli, Kenya. Am J Primatol 53:139-154. https://doi.org/10.1002/ajp.1

Alberts SC, Altmann J (2012) The Amboseli Baboon Research Project: 40 years of continuity and change. In: Kappeler PM, Watts DPGF (eds) Long-term field studies of primates. Springer, Heidelberg, pp 261-287

Alberts SC, Altmann J, Wilson ML (1996) Mate guarding constrains foraging activity of male baboons. Anim Behav 51:1269-1277. https://doi.org/10.1006/anbe.1996.0131

Alberts SC, Watts H, Altmann J (2003) Queuing and queue-jumping: long-term patterns of reproductive skew in male savannah baboons, Papio cynocephalus. Anim Behav 65:821-840. https://doi.org/10. 1006/anbe.2003.2106

Altizer S, Bartel R, Han BA (2011) Animal migration and infectious disease risk. Science 331:296-302. https://doi.org/10.1126/science. 1194694

Altizer S, Nunn CL, Thrall PH, Gittleman JL, Antonovics J, Cunningham AA, Dobson AP, Ezenwa V, Jones KE, Pedersen AB, Poss M, Pulliam JRC (2003) Social organization and parasite risk in mammals: integrating theory and empirical studies. Annu Rev Ecol Evol S 34:517-547. https://doi.org/10.1146/annurev.ecolsys.34.030102. 151725

Andersson MB (1994) Sexual selection. Princeton University Press, Princeton, NJ

Archie EA, Altmann J, Alberts SC (2012) Social status predicts wound healing in wild baboons. P Natl Acad Sci USA 109:9017-9022. https://doi.org/10.1073/pnas.1206391109

Archie EA, Tung J, Clark M, Altmann J, Alberts SC (2014) Social affiliation matters: both same-sex and opposite-sex relationships predict survival in wild female baboons. Proc R Soc B 281:20141261. https://doi.org/10.1098/rspb.2014.1261

Arlet ME, Chapman CA, Isbell LA, Molleman F, Mand R, Horak P, Carey JR (2015) Social and ecological correlates of parasitic infections in adult male gray-cheeked mangabeys (Lophocebus albigena). Int J Primatol 36:967-986. https://doi.org/10.1007/ s10764-015-9866-9

Atherholt T, Lechevallier M, Norton W, Rosen J (1998) Effect of rainfall of Giardia and crypto. J Am Water Works Assoc 90:66-80

Bartoń K (2009) MuMIn: R package for model selection and multi-model inference (version 0.12.2), https:/cran.r-project.org/web/packages/ MuMIn/index.html

Bates D, Mächler M, Bolker B, Walker S (2014) Fitting linear mixedeffects models using lme4. J Stat Softw 67:1-48 
Behnke JM, Lewis JW, Zain SNM, Gilbert FS (1999) Helminth infections in Apodemus sylvaticus in southern England: interactive effects of host age, sex and year on the prevalence and abundance of infections. J Helminthol 73:31-44

Bell G, Burt A (1991) The comparative biology of parasite species diversity: internal helminths of freshwater fish. J Anim Ecol 60:10471064

Belsley DA (1980) Regression diagnostics: identifying influential data and sources of collinearity. Wiley, New York, NY

Bonte D, Van Dyck H, Bullock JM et al (2012) Costs of dispersal. Biol Rev 87:290-312

Bowman DD (2014) Georgis' parasitology for veterinarians, 10th edn. Elsevier, St. Louis, MO

Bucknell DG, Gasser RB, Beveridge I (1995) The prevalence and epidemiology of gastrointestinal parasites of horses in Victoria, Australia. Int J Parasitol 25:711-724

Budischak SA, Neal D, Jolles AE, Ezenwa VO (2017) Differential host responses to parasitism shape divergent fitness costs of infection. Funct Ecol 32:324-333

Burnham KP, Anderson DR (2004) Multimodel inference - understanding AIC and BIC in model selection. Sociol Methods Res 33:261304

Byrne RL, Fogarty U, Mooney A, Marples NM, Holland CV (2018) A comparison of helminth infections as assessed through coprological analysis and adult worm burdens in a wild host. Int J Parasitol Parasites Wildl 7:439-444

Cabaret J, Gasnier N, Jacquiet P (1998) Faecal egg counts are representative of digestive-tract strongyle worm burdens in sheep and goats. Parasite 5:137-142

Chapman CA, Speirs ML, Hodder SAM, Rothman JM (2010) Colobus monkey parasite infections in wet and dry habitats: implications for climate change. Afr J Ecol 48:555-558

Clarke PMR, Henzi SP, Barrett L, Rendall D (2008) On the road again: competitive effects and condition-dependent dispersal in male baboons. Anim Behav 76:55-63

Clutton-Brock T (2007) Sexual selection in males and females. Science 318:1882-1885

Connor RC, Heithaus MR, Barre LM (2001) Complex social structure, alliance stability and mating access in a bottlenose dolphin superalliance. Proc R Soc Lond B 268:263-267

Coulson G, Cripps JK, Garnick S, Bristow V, Beveridge I (2018) Parasite insight: assessing fitness costs, infection risks and foraging benefits relating to gastrointestinal nematodes in wild mammalian herbivores. Phil Trans Roy Soc B 373:20170197

Creel S, Dantzer B, Goymann W, Rubenstein DR (2013) The ecology of stress: effects of the social environment. Funct Ecol 27:66-80

Darwin C (1871) The descent of man and selection in relation to sex. J. Murray, London

Dormann CF, Elith J, Bacher S, Buchmann C, Carl G, Carré G, Marquéz JRG, Gruber B, Lafourcade B, Leitão PJ, Münkemüller T, McClean C, Osborne PE, Reineking B, Schröder B, Skidmore AK, Zurell D, Lautenbach S (2013) Collinearity: a review of methods to deal with it and a simulation study evaluating their performance. Ecography $36: 27-46$

Drewe JA (2010) Who infects whom? Social networks and tuberculosis transmission in wild meerkats. Proc R Soc Lond B 277:633-642

Ezenwa VO (2004) Host social behavior and parasitic infection: a multifactorial approach. Behav Ecol 15:446-454

Ezenwa VO, Etienne RS, Luikart G, Beja-Pereira A, Jolles AE (2010) Hidden consequences of living in a wormy world: nematodeinduced immune suppression facilitates tuberculosis invasion in African buffalo. Am Nat 176:613-624

Ezenwa VO, Jolles AE (2015) Opposite effects of anthelmintic treatment on microbial infection at individual versus population scales. Science 347:175-177
Fairbanks B, Hawley DM (2012) Interactions between host social behavior, physiology, and disease susceptibility: the role of dominance status and social context. In: Demas GE, Nelson RJ (eds) Ecoimmunology. Oxford University Press, London, pp 440-467

Folstad I, Karter AJ (1992) Parasites, bright males, and the immunocompetence handicap. Am Nat 139:603-622

Gassó D, Feliu C, Ferrer D, Mentaberre G, Casas-Díaz E, Velarde R, Fernández-Aguilar X, Colom-Cadena A, Navarro-Gonzalez N, López-Olvera JR, Lavín S, Fenández-Llario P, Segalés J, Serrano E (2015) Uses and limitations of faecal egg count for assessing worm burden in wild boars. Vet Parasitol 209:133-137

Gesquiere LR, Khan M, Shek L, Wango TL, Wango EO, Alberts SC, Altmann J (2008) Coping with a challenging environment: effects of seasonal variability and reproductive status on glucocorticoid concentrations of female baboons (Papio cynocephalus). Horm Behav $54: 410-416$

Gesquiere LR, Learn NH, Simao MCM, Onyango PO, Alberts SC, Altmann J (2011a) Life at the top: rank and stress in wild male baboons. Science 333:357-360

Gesquiere LR, Onyango P, Alberts S, Altmann J (2011b) Endocrinology of year-round reproduction in a highly seasonal habitat: environmental variability in testosterone and glucocorticoids in baboon males. Am J Phys Anthropol 144:169-176

Gesquiere LR, Wango EO, Alberts SC, Altmann J (2007) Mechanisms of sexual selection: sexual swellings and estrogen concentrations as fertility indicators and cues for male consort decisions in wild baboons. Horm Behav 51:114-125

Gesquiere LR, Ziegler TE, Chen PA, Epstein KA, Alberts SC, Altmann J (2014) Measuring fecal testosterone in females and fecal estrogens in males: comparison of RIA and LC/MS/MS methods for wild baboons (Papio cynocephalus). Gen Comp Endocrinol 204:141149

Gillespie T, Lonsdorf E, Canfield E et al (2010) Demographic and ecological effects on patterns of parasitism in eastern chimpanzees (Pan troglodytes schweinfurthii) in Gombe National Park, Tanzania. Am J Phys Anthropol 143:534-544

Gillespie TR (2006) Noninvasive assessment of gastrointestinal parasite infections in free-ranging primates. Int J Primatol 27:1129-1143

Graham AL (2008) Ecological rules governing helminth-microparasite coinfection. P Natl Acad Sci USA 105:566-570

Graham MH (2003) Confronting multicollinearity in ecological multiple regression. Ecology 84:2809-2815

Griffiths EC, Pedersen AB, Fenton A, Petchey OL (2011) The nature and consequences of coinfection in humans. J Inf Secur 63:200-206

Guernier V, Hochberg ME, Guegan J (2004) Ecology drives the worldwide distribution of human diseases. PLoS Biol 2:740-746

Habig B, Archie EA (2015) Social status, immune response and parasitism in males: a meta-analysis. Phil Trans Roy Soc B 370:20140109

Habig B, Doellman MM, Woods K, Olansen J, Archie EA (2018) Social status and parasitism in male and female vertebrates: a meta-analysis. Sci Rep 8:3629

Hahn N, Proulx D, Muruthi P, Alberts S, Altmann J (2003) Gastrointestinal parasites in free-ranging Kenyan baboons (Papio cynocephalus and P. anubis). Int J Primatol 24:271-279

Halvorsen O (1986) On the relationship between social status of host and risk of parasitic infection. Oikos 47:71-74

Hamilton WD, Zuk M (1982) Heritable true fitness and bright birds: a role for parasites. Science 218:384-387

Hausfater G (1975) Dominance and reproduction in baboons (Papio cynocephalus). A quantitative analysis. Contrib Primatol 7:1-150

Hausfater G, Takacs D (1987) Structure and function of hindquarter presentations in yellow baboons (Papio cynocephalus). Ethology 74: 297-319

Hausfater G, Watson DF (1976) Social and reproductive correlates of parasite ova emissions by baboons. Nature 262:688-689 
Hernandez AD (1995) Host grooming and the transmission strategy of Heligmosomoides polygyrus. J Parasitol 81:865-869

Holmes JC (1961) Effects of concurrent infections on Hymenolepis diminuta (Cestoda) and Moniliformis dubius (Acanthocephala). I. General effects and comparison with crowding. J Parasitol 47: 209-216

Huffman M, Gotoh S, Turner L, Hamai M, Yoshida K (1997) Seasonal trends in intestinal nematode infection and medicinal plant use among chimpanzees in the Mahale Mountains, Tanzania. Primates $38: 111-125$

Jolles AE, Ezenwa VO, Etienne RS, Turner WC, Olff H (2008) Interactions between macroparasites and microparasites drive infection patterns in free-ranging African buffalo. Ecology 89:22392250

Kuntz RE, Moore JA (1973) Commensals and parasites of African baboons (Papio cynocephalus L. 1766) captured in Rift Valley Province of central Kenya. J Med Primatol 2:236-241

Kuznetsova A, Brockhoff PB, Christensen, RHB (2015) lmerTest: tests in linear mixed effects models. R package version 2.0, https://cran.rproject.org/web/packages/lmerTest/index.html

Lafferty KD (2009) The ecology of climate change and infectious diseases. Ecology 90:888-900

Larsen E, Stewart GL, Niederkorn JY (1991) Trichinella pseudospiralis overcomes innate resistance of the Chinese hamster to Trichinella spiralis. Parasitology 103:465-470

Lea AJ, Akinyi MY, Nyakundi R, Mareri P, Nyundo F, Kariuki T, Alberts SC, Archie EA, Tung J (2018) Dominance rank-associated gene expression is widespread, sex-specific, and a precursor to high social status in wild male baboons. P Natl Acad Sci USA 115:E12163E12171

Leclaire S, Faulkner CT (2014) Gastrointestinal parasites in relation to host traits and group factors in wild meerkats Suricata suricatta. Parasitology 141:925-933

Lee KA (2006) Linking immune defenses and life history at the levels of the individual and the species. Integr Comp Biol 46:1000-1015

MacIntosh AJJ, Jacobs A, Garcia C, Shimizu K, Mouri K, Huffman MA, Hernandez AD (2012) Monkeys in the middle: parasite transmission through the social network of a wild primate. PLoS One 7:e51144

McDonald DB (2007) Predicting fate from early connectivity in a social network. P Natl Acad Sci USA 104:10910-10914

Meade BJ (1983) Host-parasite dynamics among Amboseli baboons. $\mathrm{PhD}$ thesis, Virginia Polytechnic Institute

Michael E, Bundy DAP (1989) Density dependence in establishment, growth and worm fecundity in intestinal helminthiasis: the population biology of Trichuris muris (Nematoda) infection in CBA/Ca mice. Parasitology 98:451-458

Mignatti A, Boag B, Cattadori IM (2016) Host immunity shapes the impact of climate changes on the dynamics of parasite infections. P Natl Acad Sci USA 113:2970-2975

Moller AP, Christe P, Lux E (1999) Parasitism, host immune function, and sexual selection. Q Rev Biol 74:3-20

Muehlenbein MP, Bribiescas RG (2005) Testosterone-mediated immune functions and male life histories. Am J Hum Biol 17:527-558

Mundry R, Nunn CL (2009) Stepwise model fitting and statistical inference: turning noise into signal pollution. Am Nat 173:119-123

Mwangi TW, Bethony JM, Brooker S (2006) Malaria and helminth interactions in humans: an epidemiological viewpoint. Ann Trop Med Parasitol 100:551-570

Müller-Graf CDM, Collins DA, Woolhouse MEJ (1996) Intestinal parasite burden in five troops of olive baboons (Papio cynocephalus anubis) in Gombe Stream National Park, Tanzania. Parasitology 112:489-497

Nakahashi W (2016) Coevolution of female ovulatory signals and malemale competition in primates. J Theor Biol 392:12-22
Nava-Castro K, Muniz-Hernandez S, Hernandez-Bello R, MoralesMontor J (2011) The neuroimmunoendocrine network during worm helminth infections. ISJ 8:143-152

Negro SS, Caudron AK, Dubois M, Delahaut P, Gemmell NJ (2010) Correlation between male social status, testosterone levels, and parasitism in a dimorphic polygynous mammal. PLoS One 5:e12507

Nunn CL, Altizer S (2006) Infectious diseases in primates: behavior, ecology, and evolution. Oxford University Press, Oxford

Nunn CL, Dokey AT-W (2006) Ranging patterns and parasitism in primates. Biol Lett 2:351-354

Papier K, Williams GM, Luceres-Catubig R, Ahmed F, Olveda RM, McManus DP, Chy D, Chau TNP, Gray DJ, Ross AGP (2014) Childhood malnutrition and parasitic helminth interactions. Clin Infect Dis 59:234-243

Patterson J, Ruckstuhl K (2013) Parasite infection and host group size: a meta-analytical review. Parasitology 140:803-813

Pedersen AB, Fenton A (2007) Emphasizing the ecology in parasite community ecology. Trends Ecol Evol 22:133-139

Pettifer HL (1984) The helminth fauna of the digestive tracts of chacma baboons, Papio ursinus, from different localities in the Transvaal. Onderstepoort J Vet 51:161-170

Prugnolle F, de Meeus T (2002) Inferring sex-biased dispersal from population genetic tools: a review. Heredity 88:161-165

R Core Team (2017) R: a language and environment for statistical computing. R Foundation for Statistical Computing, Vienna http://www. R-project.org

Rifkin JL, Nunn CL, Garamszegi LZ (2012) Do animals living in larger groups experience greater parasitism? A meta-analysis. Am Nat 180:70-82

Rimbach R, Bisanzio D, Galvis N, Link A, Di Fiore A, Gillespie TR (2015) Brown spider monkeys (Ateles hybridus): a model for differentiating the role of social networks and physical contact on parasite transmission dynamics. Phil Trans Roy Soc B 370:20140110. https://doi.org/10.1098/rstb.2014.0110

Rothman JM, Pell AN, Bowman DD (2008) Host-parasite ecology of the helminths in mountain gorillas. J Parasitol 94:834-840

Schneider-Crease I, Griffin RH, Gomery MA, Bergman TJ, Beehner JC (2017) High mortality associated with tapeworm parasitism in geladas (Theropithecus gelada) in the Simien Mountains National Park, Ethiopia. Am J Primatol 79 published online, doi:https://doi. org/10.1002/ajp.22684

Schülke O, Bhagavatula J, Vigilant L, Ostner J (2010) Social bonds enhance reproductive success in male macaques. Curr Biol 20: $2207-2210$

Setchell JM, Bedjabaga IB, Goossens B, Reed P, Wickings EJ, Knapp LA (2007) Parasite prevalence, abundance, and diversity in a semi-freeranging colony of Mandrillus sphinx. Int J Primatol 28:1345-1362

Smith EO (1992) Dispersal in sub-Saharan baboons. Folia Primatol 59: $177-185$

Stancampiano L, Gras LM, Poglayen G (2010) Spatial niche competition among helminth parasites in horse's large intestine. Vet Parasitol 170:88-95

Strait K, Else JG, Eberhard ML (2012) Parasitic diseases of nonhuman primates. In: Abee C, Mansfield K, Tardif S, Morris T (eds) Nonhuman primates in biomedical research. Academic Press, Oxford, pp 197-297

Telfer S, Lambin X, Birtles R, Beldomenico P, Burthe S, Paterson S, Begon M (2010) Species interactions in a parasite community drive infection risk in a wildlife population. Science 330:243-246

Tung J, Archie EA, Altmann J, Alberts SC (2016) Cumulative early life adversity predicts longevity in wild baboons. Nat Commun 7:11181. https://oi.org/10.1038/ncomms11181

Tung J, Charpentier MJE, Garfield DA, Altmann J, Alberts SC (2008) Genetic evidence reveals temporal change in hybridization patterns in a wild baboon population. Mol Ecol 17:1998-2011 
Vitone ND, Altizer S, Nunn CL (2004) Body size, diet and sociality influence the species richness of parasitic worms in anthropoid primates. Evol Ecol Res 6:183-199

Warburton EM, Kohler SL, Vonhof MJ (2016) Patterns of parasite community dissimilarity: the significant role of land use and lack of distance-decay in a bat-helminth system. Oikos 125:374-385

Wilcox JJS, Lane-Degraaf KE, Fuentes A, Hollocher H (2015) Comparative community-level associations of helminth infections and microparasite shedding in wild long-tailed macaques in Bali, Indonesia. Parasitology 142:480-489

Publisher's note Springer Nature remains neutral with regard to jurisdictional claims in published maps and institutional affiliations. 